\title{
Aspects of Audit
}

\section{5: Looking forward to audit}

\author{
CHARLES D SHAW
}

\begin{abstract}
Summary and conclusions
Whatever the misgivings of individual doctors, the formal support being given by professional bodies suggests that medical audit will become established in Britain. It is therefore appropriate to heed the advice of pioneers in the field in choosing methods and topics for audit. Practical problems can be anticipated because of the inadequacy of medical records, retrieval systems, and comparable information on practice patterns and evaluation of traditional processes of patient care. The criterion system of audit may provide a common standard for effective review. This can be used for any group of patients with some characteristic in common. It requires good records and a good records staff. Whatever method is adopted, central support should come from the royal colleges, with community physicians and clinical tutors assisting clinicians at the local level.
\end{abstract}

\section{Introduction}

Consumer organisations, community health councils, and other thoughtful lay bodies are increasing the pressure for accountability of health care, and this is echoed by cries from within the medical profession that the profession should be seen to examine its own work critically. Many doctors view audit not with delight but with resignation and the hope that, if it is inevitable, something good will come of it. Perhaps it is the price we pay for being in the profession with the fastest rate of change.

Few formal medical bodies during the past five years have failed to endorse the concept of audit by the profession. The third report of the Joint Working Party on the Organisation of Medical Work in Hospitals avoided the specific phrase medical audit, but voluntary peer review was explicitly supported by the Alment Committee on competence to practise, the working party of the Welsh General Medical Services Committee, and most recently the Royal Commission on the National Health Service. In their evidence to the royal commission the Royal Colleges of Physicians of London, Surgeons of England, and General Practitioners all advocated some form of audit as a method of education or evaluation. In contrast the BMA was tepid in its support, but it was urged at the conference of senior hospital staff in 1978 and at the Annual Representative Meeting in 1979 that practical approaches to audit be explored. So it looks as if the issue is no longer whether medical audit will

Gloucestershire Area Health Authority, Cheltenham GL50 2QN, Gloucestershire

CHARLES D SHAW, MB, BS, senior registrar in community medicine (previous appointments: representative for the Canadian Council on Hospital Accreditation, Ottawa, Canada, and medical director, King Edward VII Memorial Hospital, Bermuda) become established in Britain but what form it will take. And this equally fertile issue will no doubt provide medical journals with editorial pabulum for several years.

Authors who have faced the problems of implementing audit have drawn up guidelines, based on their experience, on its purpose and practice. These vary in emphasis, but factors common to the different sources are as follows:

purpose-should be educational and shown to be relevant to patient care;

control-should be by clinical peers and participation should be voluntary;

standards - should be set locally by participating clinicians;

method-should be non-threatening, interesting, objective, and repeatable (for follow-up);

resources-should be cheap and simple and cause minimal disturbance to clinical work;

records-adequate clinical content and retrieval systems are essential.

Although most of these points have been covered earlier in this series, little has been included about the choice of method or the practical needs of audit.

\section{Topics for audit}

The long-standing question of whether to focus on outcome of care or on the process of care is still unresolved but has recently been summarised by $\mathrm{McColl}$ (1979). Another point for debate is whether audit should be performed on practice, practitioner, or health care in general. Although they provide food for philosophy, these issues have little practical application since the individual elements cannot be realistically separated from each other. Different approaches are appropriate to different problems.

An ideal subject for audit would be a common, well-defined, clinically significant diagnosis or treatment where management has a clear effect on outcome. It is obvious that few subjects are ideal and certainly do not represent the whole range of clinical practice, but several close approximations may be suggested (see tables I and II). Though not all aspects of medicine lend themselves to audit, this does not diminish the value of what is learned from those that do. Apart from studies in general practice and of inpatient care in acute hospitals, there is little published experience in Britain. The audit of long-term

TABLE I-Some topics appropriate for audit in acute hospitals

\begin{tabular}{ll}
\hline Use of antibiotics & Appendicectomy \\
Blood transfusions & Cholecystectomy \\
Cardiac arrest & Inguinal hernia \\
Hypertension & Massive gastrointestinal bleeding \\
Anaemia & Pre-anaesthetic assessment \\
Urinary tract infection & Obstetric flying squad calls \\
Bacterial pneumonia & Induction of labour \\
Paediatric gastroenteritis & \\
\hline
\end{tabular}


hospital care, community health, and outpatient care (including casualty) presents different problems requiring different solutions.

\section{Information and records}

One issue on which the practitioners and philosophers are universally agreed is that audit quickly shows how inadequate the average traditional medical record is for explaining what happened to patients and why. This is perhaps most evident in chronic illness managed by various team members in primary care. Some remedies are the use of A4 filing, flow sheets, and problem-oriented records. But changing record systems is

TABLE II-Some topics appropriate for audit in general practice

\begin{tabular}{ll}
\hline Hypertension & Pyrexia of unknown origin \\
Diabetes & Surveillance of elderly at home \\
Thyroid disease & Backache \\
Leg ulcers & Urinary tract infection \\
Otitis media & Depression \\
\hline
\end{tabular}

sufficiently expensive, time consuming, and daunting that many doctors would first need to be convinced that the upheaval would be rewarded by improved patient care. As a compromise, problem lists and team participation-two main features of problem-oriented records-can be applied to traditional records but are not essential to audit.

Another requirement for audit is a system of retrieving the records of patients with a given diagnosis, treatment, or procedure. In hospitals the Hospital Activity Analysis and Mental Health Enquiry may be supplemented by registers kept in individual departments for inpatients, but comparable sources for outpatients are limited. Similar problems in general practice have been met by using diagnostic registers, colour tabulations, and feature card systems.

Information about practice patterns and about the evaluation of traditional processes of patient management requires knowledge that can only be built up by a central collection of data and by controlled research.

\section{Choosing a method of audit}

Examples of several approaches were given earlier in this series in relation to hospitals and general practice. Some of those were based on informal, subjective reviews of sample cases-a low-key, straightforward approach that may encourage participants to break the ice and gain confidence in peer review. Experience in North America, however, has shown the limitations of this method. Because the method is subjective, small groups tend to avoid drawing conclusions or recommending actions that are likely to lead to confrontations with colleagues. In addition, by taking samples only a small proportion of cases can be reviewed, which is costly in terms of the doctors' time and gives only a limited view of patterns of practice.

\section{CRITERION AUDIT}

Such problems led to the development of "criterion audit," which is now the preferred method in the USA and Canada since it can be applied to any group of patients with some characteristic in common. Having chosen a topic for review, the participating doctors agree on a limited number of tangible elements that they consider to be critical to the process and outcome of management. For example, an audit of the treatment of patients with pneumonia in hospital might include referring to specific elements of diagnosis, treatment, and resolution and defining undesired complications.
These criteria are explicitly formulated so they can be applied by medical records staff to individual patient notes and recorded as either present or absent. In this way, 30 to 50 records can be reviewed, but only a small minority, which for some reason vary from the agreed criteria, are examined by the clinicians themselves. A large proportion of the records showing variation are then seen to be justified clinically, leaving only a few that are considered by the group to show specific defects. On this basis the group can make appropriate recommendations for future management.

On first sight this approach seems to be unnecessarily complicated and restrictive, but in practice it is not and it has many advantages in addition to avoiding the potential problems of subjective, selective audit. Discussing the essential criteria before the audit is performed reduces any perceived need for self-justification and is in itself an education since it requires agreement on issues that may otherwise be considered too basic to be debated. However, since such explicit criteria have been condemned in Britain for producing rigid conformity in patient management, it must be emphasised that their purpose is merely to cull records for clinical review. They do not provide a prescription for managing patients.

Like committees, an audit that does not produce explicit conclusions and explicit recommendations for action is useless. This formal approach also permits the same study to be repeated later so that direct comparisons can be made to show whether the recommended actions were actually effective in resolving the previous weaknesses.

Clerical staff already assist in tabulating data in primary care, but criterion audit relies heavily on medical records staff in hospitals as well. In the Canadian equivalent of district hospitals it is becoming usual for one member of the records staff to be trained and employed for this purpose. This "records analyst" also handles data for the equivalent of the Hospital Activity Analysis, which provides much of the information for case retrieval.

In Britain, where there is no equivalent to the records analyst, health authorities must recognise that formal audit cannot be established without the help of adequately staffed records departments. Some consolation from the implications of the cost may come from the analogy that in industry it has long been accepted that "quality control" is an integral part of the budget.

Finally, it should be stressed that the role of medical records staff in criterion audit is to collect and tabulate data from clinical records, using the criteria defined by the doctors, and not to exercise clinical judgment.

\section{Introduction of audit}

In Australia, the United States, and Canada the development of audit has been fostered in hospitals by national systems of hospital accreditation. These non-governmental bodies not only visit all types of hospitals every two to three years, but they also publish guidelines on good practice in running hospitals. They are thus well placed to advise and assist in the development of audit. Although in Britain the Health Advisory Service could fulfil part of this role, encouragement would come most appropriately from the royal colleges and faculties in co-ordinating pilot studies and seminars. At the local level assistance in establishing audit should come from community physicians and, because the primary role of audit is to educate, from postgraduate tutors. Community physicians and postgraduate tutors should take part only at the request of clinicians who seek to implement audit, and their role must be to advise rather than to perform the audit.

A medical organisation for carrying out audit and for implementing and following up recommendations for change is also needed. The cogwheel system was intended for this purpose, and doctors in group practice or health centres have an advantage. But special problems are faced by doctors isolated 
by distance or specialty and they may require co-ordination by local medical committees or regional departments.

The requirements for audit may be summarised as information, resources, and willingness to participate. There is little that is new about the concept of review, except the terminology and, more visibly, the formal methods. The principal ingredient is one of attitude-as an editorial in the Lancet recently stated, "Without a willing spirit of enquiry, audit is worthless."

\section{Bibliography}

Birmingham Research Unit of the Royal College of General Practitioners. Self-evaluation in general practice $f R$ Coll Gen Pract 1977;27:265-70.

British Medical Association. Evidence of Council to the Royal Commission on the National Health Service. Br Med F 1977;i:299-334.

British Medical Association, Annual Representatives Meeting, 1979. Medical audit: ARM calls for practical recommendations. $\mathrm{Br} \mathrm{Med} \mathcal{F}$ 1979 ;ii:143.

Buck C, Fry J, Irvine DH. A framework for good primary medical carethe measurement and achievement of quality. $\mathcal{F} R$ Coll Gen Pract $1974 ; 24: 599-604$.

Canadian Council on Hospital Accreditation. Guide de Contrôle Médical. Toronto, 1976

Clark MR, MacIntyre KA. Patient care appraisal as a guide for the design of continuing medical education. Can Med Assoc 7 1978;118:131-8.

Committee of enquiry into competence to practise. Report. Alment EAJ, chairman. London, 1976.

Conference of senior hospital staff, 1978. Medical audit working party's report. Br Med F 1979;ii:1603.

Dudley HAF. Necessity for surgical audit. $B r$ Med $\mathcal{F} 1974$;i :275-7.

Editorial. Controlling quality. Br Med f $1974 ;$ iii: 704 .

Editorial. Medical audit in general practice. Lancet $1980 ; \mathrm{i}: 23-4$.

Fernow LC, McColl I. The state of British medicine-medical audit. IR Soc Med 1978;71:787-90.

General Medical Services Committee (Wales). Report of a working party on medical audit by peer review. 1975.

Irvine D. Contemporary professional practice. In: McLachlan G, ed. $A$ question of quality? Oxford: Oxford University Press, 1976:65-96.
Irving $M$, Temple J. Surgical audit: one year's experience in a teaching hospital. Br Med f 1976;ii:746-7.

Johnson R. Medical audit. Lancet $1975 ; \mathrm{i}: 679$

Joint working party on the organisation of medical work in hospitals. Third report. London: HMSO, 1974.

Kirk C, Lee-Jones $M$. Medical records, medical audit and community hospitals. F $R$ Coll Gen Pract 1976;26:143-6.

McColl I. Observations on the quality of surgical care. In: McLachlan G, ed. A question of quality? Oxford: Oxford University Press 1976:51-61.

McColl I. Medical audit in British hospital practice. Br f Hosp Med 1979; $22: 485-9$.

McColl I, Fernow LC, Mackie C, Rendall M. Communication as a method of medical audit. Lancet 1976;i:1341-4.

McDowell I, Martini CJM. Problems and new directions in the evaluation of primary care. Int $\mathcal{F}$ Epidemiol $1976 ; 5: 247-50$.

Mourin K. Audit in general practice. $f$ R Coll Gen Pract 1975;25:682-3.

Mourin K. Auditing and evaluation in general practice. $\mathcal{F} R$ Coll Gen Pract $1976 ; 26: 726-33$.

Murray JH, Swanson AL, Knauf C. Canadian Council on Hospital Accreditation project shows clinical appraisal can be satisfying. Can Med Assoc F 1977;166:200-5.

Reilly PM, Patten MP. An audit of prescribing by peer review. $\mathcal{F} R$ Coll Gen Pract 1978;28:525-30.

Royal College of General Practitioners. Evidence to the Royal Commission on the NHS. F R Coll Gen Pract 1977;27:197-206.

Royal College of Physicians of London. Evidence to the Royal Commission on the National Health Service. London, 1977.

Royal College of Surgeons of England. Evidence to the Royal Commission on the National Health Service. London: 1977 :part II.

Royal Commission on the National Health Service. Measuring and controlling quality. In: Report of the Royal Commission. London: HMSO, 1979:173-7.

Ryan MP, Buchan IC, Buckley EG. Medical audit-a preliminary report from general practice. $\mathcal{F} R$ Coll Gen Pract 1979;29:719-22.

Sheldon MG. Self-audit of prescribing habits and clinical care in general practice. $\mathcal{F} R$ Coll Gen Pract 1979;29:703-11.

Stevens JL. Quality of care in general practice: can it be assessed ? $\mathcal{F}$ Coll Gen Pract 1977;27:455-66.

Wilson LL, Larkins N. Peer review. Med 7 Aust 1977;i, suppl 2:7-24.

This is the final article in a series of five on medical audit in Britain. Readers may obtain specific references from the author.

No reprints will be available.

\section{MATERIA NON MEDICA}

\section{Pink elephants}

We were a small group sailing in the Mauretania from Southampton to New York. There we would meet the main party who had, unwisely in my opinion, gone by air rather than sample the joys of ocean travel. In New York we would start a four-week visit to several leading American medical centres. The voyage was delightful. The Atlantic was kind, the sun shone most of the time, and the Mauretania was extremely comfortable. In general we took only a mild interest in the many social activities. One morning, however, a fancy dress parade was announced for that evening. No one mentioned it until we were having a drink before lunch when the bright lad of the party, with a faraway look in his eyes, suddenly said "pink elephants."

He explained that he thought there should be a troupe of two pink elephants, the interior and motive power of each being supplied by two gynaecologists; two oriental attendants; and a ringmaster. The exterior and trunks of the elephants would be made from steamer rugs, pink side out, the eyes and tusks from menus and the tails from ship's rope. The attendants, our wives, would wear saris made from brightly coloured cabin bedspreads, and the ringmaster, a Philadelphia redhead conscripted for the purpose, a dinner jacket.

The necessary material was rapidly collected for a rehearsal on deck. Our mentor, who seemed to know a lot about elephants, showed us how they walked. In pairs we plodded round the promenade deck, not in costume, causing interest, amusement, and speculation among the other passengers. One old lady, however, who quite clearly understood what we were doing, said to me "I think you must have lived in India."

On the night, I believe that things went well. Forming the front half of one elephant I could not see a thing. I was vaguely conscious of laughter and muffled applause, and I still treasure my share of our prize.
We arrived in New York in a heat wave. That day 12 passenger liners docked within 10 hours. This was an all-time record for the port of New York and more than 9000 passengers disembarked. Alas, we are never likely to see anything remotely comparable again.-ARTHUR SUTHERLAND (gynaecologist, Glasgow).

\section{Communications}

The medical profession spends a lot of its time nowadays in selfcriticism for its alleged "poor communication," and much of this is justified. But we are not alone. Reading through the programme notes at a Philharmonic concert last night, I wondered what to make of such comments on Symphony No 2 in C major, op 61 by Schumann: "He was much preoccupied with the purely musical problem of how to weld the separate movements of a large-scale work into a closely unified whole by thematic metamorphosis and interquotation."

Presumably he managed it successfully because, we read, the Scherzo "again introduces minor-tinged $\mathbf{E}$ flats and other chromaticisms to heighten the unrest of its petulant main theme. But there are two trios to ease the tension, one skittish in $G$ and the other lyrical in $\mathrm{C}$, and the movement ends with a triumphant reassertion of the motto." Now I have no doubt that all this makes sense to those of you who are musicians, but I presume you would understand the music anyway without the need for programme notes, which I have always imagined were intended for the ordinary concert goer. So perhaps we could make a bargain-if I promise to continue to give barium meal and enema instructions in simple-to-understand English, will the compilers of concert notes try to make theirs more intelligible un poco mosso or preferably allegro con brio?-MYER GOLDMAN (consultant radiologist, Liverpool). 